\title{
Incidental Finding of Microfilaria in Blast Crisis of Chronic Myeloid Leukemia- A Rare Entity
}

\author{
Deepa $\mathbf{R}^{1 *}$, Sandip $\mathbf{K}^{2}$ and Shruti ${ }^{3}$ \\ ${ }^{1}$ Assistant Professor Department of Pathology, IMS, BHU, Varanasi, India \\ ${ }^{2}$ Associate Professor, Department of Pathology, IMS, BHU, Varanasi, India \\ 3 Junior Resident, Department of Pathology, IMS, BHU, Varanasi, India
}

*Corresponding author: Deepa Rani, Assistant Professor Department of Pathology, IMS, BHU, Varanasi, India, Tel: 9889532440; E-mail: drdeepabhaskar@gmail.com

\section{Case Report \\ Volume 2 Issue 1}

Received Date: September 09, 2017

Published Date: January 10, 2018

DOI: $10.23880 /$ cprj-16000107

\section{Abstract}

Filariasis is a major public health concern in tropical and subtropical countries including India. There have been very few case reports of incidental filariasis in the smears in patients with hematological malignancies. We are presenting a case of blastic phase of chronic myeloid leukemia (CML) with associated filariasis.

Keywords: Spleenomegaly; Microfilariae; W. bancrofti; Elephantiasis

\section{Case History}

Patient was 50 year female, a follow up case of CML for five years. Patient had no history of fever, lymphadenitis or lymphangitis the only complain was generalised weakness and abdominal swelling due to spleenomegaly [1]. General blood picture was examined one month a part. In Peripheral blood examination there was no eosinophilia. In her first report blast were $8 \%$ and she was in chronic phase, after one month of that blast were $17 \%$ she gone in accelerated phase, now she had $23 \%$ blast in peripheral smear and diagnosed as in blast crisis of CML. When these smears were examined a few sheathed microfilariae were seen in the blood smears. They were morphologically characterized as the microfilariae of W. bancrofti, as they lacked terminal nuclei which are the common parasite with uncommon association.

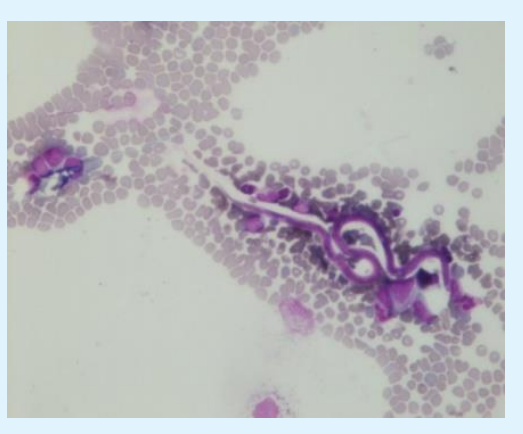

Figure 1: Microfilaria with few blast- 40x

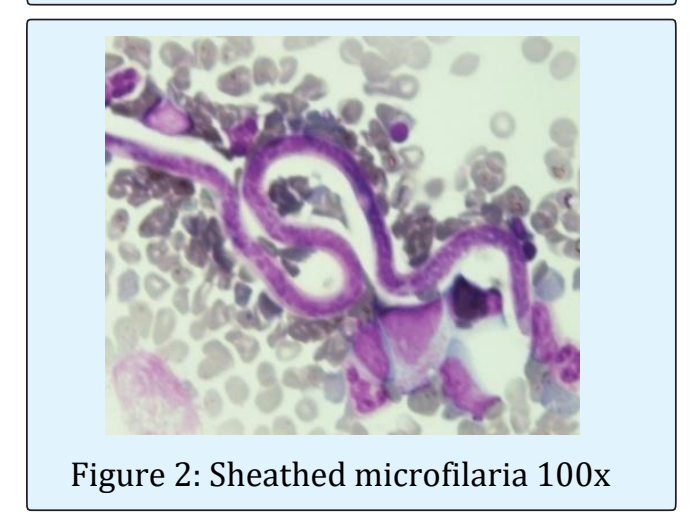




\section{Discussion}

Filariasis is a major health problem in endemic areas. In humans $W$. bancrofti is the most common filarial parasite which causes lymphatic filariasis [2]. In the natural history of lymphatic filariasis, the adult worm lodges in the lymphatics and the microfilariae circulate in the blood stream [2]. Lymphatic filariasis commonly presents as lymphangitis, elephantiasis and peripheral blood eosinophilia [3]. During their circulation in the peripheral blood, the microfilariae may get lodged in various organs and body fluids and be picked up in the cytological samples [3].

There are many reports of finding the microfilaria incidentally on the aspiration smears even in the absence of clinical signs and symptom Filariasis [4-7]. Asymptomatic microfilaremia is relatively common in India [8]. The coexistence of microfilaria and malignancy may be coincidental.

There are very few case reports of incidental finding of filariasis with haematological malignancy. Pahwa et al. reported a case of filariasis with blast crisis of CML in bone marrow smears [9]. In her case there were no eosinophilia, in our case also there was no eosinophilia and we found the microfilaria in peripheral smear during follow up examination. The absence of peripheral blood eosinophilia in these cases may be due to altered immune response secondary to malignancy or due to the oxidative stress associated with filariasis [10].

\section{Conclusion}

Hence it is concluded that all the smears should be examined carefully to find such an incidental finding. It is also concluded that it is not necessary to find the clinical sign and symptoms of filariasis in every case. The association of filaremia in haematological malignancy is rare so must be looked carefully.

\section{References}

1. Arundhati, Kumar A, Kumar R (2011) Acute lymphoblastic leukaemia with microfilaria: A rare coincidence in bone marrow aspirate. Indian J Hematol Blood Transfus 27(2): 111-112.

2. Park K (2011) Epidemiology of communicable diseases. In: Park K (Ed.), Park's text book of preventive and social medicine. 21. New Delhi: Bhanot publishers, pp: 245-246.

3. Pradhan S, Lahiri VL, Ethence BR, Singh KN (1976) Microfilariae of Wucheria bancrofti in bone marrow smear. Am J Trop Med Hyg 25(1): 199-200.

4. Yenkeshwar PN, Kumbhalkar DT, Bobhate SK (2006) Microfilariae in fine needle aspirates: a report of 22 cases. Indian J Pathol Microbiol 49(3): 365-369.

5. Sharma S, Rawat A, Chowhan A (2006) Microfilariae in bone marrow aspiration smears their correlation with marrow hypoplasia: a report of six cases. Indian J Pathol Microbiol 49(4): 566-568.

6. Shenoi U, Pai RR, Pai U, Nandi GK, Adhikari P (1998) Microfilariae in bone marrow aspiration smears. Acta Cytol 42(3): 815-816.

7. Panja M, Ganguly S, Kar AK, Chhetri MK (1987) Atypical filariasis. J Assoc Physicians India 35(8): 596-597.

8. Sabesan S, Vanamail P, Raju K, Jambulingam P (2010) Lymphatic filariasis in India: Epidemiology and control measures. J Postgrad Med 56(3): 232-238.

9. Suniti P, Annapurna S, Ashu S, Daga MK, Tejinder S (2015) Blastic Phase of CML with Microfilaria: A Rare Case Report. J Clin Diagn Res 9(1): ED09-ED10.

10. Pal BK, Kulkarni S, Bhandari Y, Ganesh BB, Goswami $\mathrm{K}$, et al. (2006) Lymphatic filariasis: a possible pathophysiological nexus with oxidative stress. Trans R Soc Trop Med Hyg 100: 650-655. 